\title{
Use of Refusal Strategies among Saudi EFL Students: An Investigative Study
}

\author{
Ahmad Hatim Qadi ${ }^{1}$ \\ ${ }^{1}$ English Language Center, Umm Al-Qura University, Makkah, Saudi Arabia \\ Correspondence: Ahmad Hatim Qadi, English Language Center, Umm Al-Qura University, Makkah, Saudi \\ Arabia.
}

Received: April 15, 2021

Accepted: June 3, 2021

Online Published: June 9, 2021

doi: $10.5539 /$ elt.v14n7p27

URL: https://doi.org/10.5539/elt.v14n7p27

\begin{abstract}
The current study seeks to probe the use of refusal strategies and their frequency among Saudi EFL students of Bachelor of Science (BS) at Moon University (pseudonym), Saudi Arabia. Through a convenient sampling procedure, 20 students were selected, and Discourse Completion Test (DCT) was administered. This test comprised 12 situations eliciting refusals to suggestions, requests, offers, and invitations. Their answers were then coded using the refusal strategies categories laid down by Beebe, Takahashi \& Uliss-Weltz (1990) and were analyzed via content analysis. Each participant's refusal strategy for each speech act was analyzed using descriptive statistics, to discover exact frequency counts. The results indicated that the indirect refusal strategies were adopted by Saudi EFL students with greater frequency than the direct strategies even though Saudi culture is characteristically inclined towards directness resulting in numerous face-threatening acts. The results demonstrated the tendency towards the use of adjuncts by EFL students which to some extent indicated the cultural grooming of interlocutors. Moreover, lack of pragma-linguistic competence was reflected in flawed and ambiguous syntactic structures which impacted the clarity of meaning. The findings also suggested that in this globalized world where cross-cultural communication is unavoidable, the teaching of English should be geared towards the development of both pragma-linguistic and socio-pragmatic competence among EFL students.
\end{abstract}

Keywords: refusal strategies, pragmatics, EFL, Saudi Arabia

\section{Introduction}

Pragmatic competence, defined as "the ability to use language forms in a wide range of environments, factoring in the relationships between the speakers involved and the social and cultural context of the situation" (Lightbown \& Spada, 2013), has always been a debatable issue in foreign language teaching. Proficient speakers of a second language, despite their command over vocabulary and grammar, may not be able to produce socially and culturally appropriate language in various situations. The non-proficient multilingual and multicultural EFL students are not only jeopardized by their pragma-linguistic incompetence while speaking but also obstructed by their socio-pragmatic incompetence. To make up for their shortcomings in pragmatic knowledge these students succumb to pragmatic borrowing from their first language to the target language. They use direct translation from their mother language and then add their cultural perspectives during their communication in the English language. Hence, their speech is replete with pragmatic errors - a situation that consequently leads to pragmatic failure or communication breakdown. This is precisely why the integration of pragmatics with language teaching should be considered rudimentary.

Searle (1969) categorizes speech act as a core trait of linguistic conduct. Speakers consistently use an array of speech acts while talking, such as to formulate requests, express complaints, apologies, refusals, compliments or thanks. Of all the speech acts, one of the most challenging ones is refusal, not only in a foreign language but also in one's mother tongue. Brown and Levinson (1987) consider the appropriate manner of refusal a yardstick for pragmatic competence of a language. Owing to its sensitive nature and being a directly face-threatening act (FTA), it can easily create displeasure with an addressee. Refusal is defined as the "face-threatening act that tends to disrupt harmony in relationships" (Umale, 2011, p. 18). Since refusal contradicts the interlocutors' "expectations and is often realized through indirect strategies, it requires a high level of pragmatic competence" (Chen, 1996). Refusals, if miscommunicated or misunderstood, can easily hamper personal links and social circles. 
Umale (2011) asserts that the positive and negative face of the interlocutors in a situation can be negatively affected and can lead to communication breakdown. It is essential to investigate how the cultural milieu and language orientation of EFL students influences their usage of speech acts, in the backdrop of technological and global convergence of modern times since "cross-cultural communication is becoming an integral part of life" (Umale, 2011, p. 19). Besides, this study is focused on the premise that any form of refusal, to an offer, opinion, or invitation, can inherently drive the social relations to disturbance. This inadvertently points to the fact that the manner in which speech acts are executed necessitates prudence along with appropriateness.

Every culture has its unique set of refusal strategies or speech acts. However, the strategies employed by EFL students from diverse cultural and linguistic milieus could be a conspicuously researchable domain for it might highlight variations between the same acts in various cultures. The present study intends to explore how appropriately and dexterously Saudi EFL graduate students use English speech acts while dealing with refusals to suggestions, invites, requests, and offers in diverse situations involving interactants of varying social cadres (e.g., manager, executives, etc.), same status (e.g., peers, friends, etc.) and people with lower social status (e.g., maid, driver, etc.)

\subsection{Research Question}

The current study aims at investigating various kinds of refusal strategies opted by EFL speakers of Saudi origin, communicating in English. This study is based on these research queries.

1) What kinds of refusal strategies do Saudi EFL speakers use when refusing?

2) What is the frequency and ratio of usage of these refusal strategies?

\subsection{Research Objectives}

To enquire about the research questions, the study sets the following objectives:

1) To identify refusal strategies Saudi EFL students use while refusing.

2) To gauge the frequency of refusal strategies Saudi EFL students use when refusing in English.

\section{Literature Review}

\subsection{Speech Acts and Their Classifications}

By definition, speech acts refer to those characteristic groups of utterances that speakers use to carry out certain purposes, i.e., to thank, complain, apologize, request, refuse, etc. Austin (1962) initially proposed speech act theory in his book titled, "How to Do Things with Words." This theory was later elaborated and furnished in 1969 by J.R. Searle, an American philosopher. This theory considers the extent to which speech performances serve different acts, such as perlocutionary, locutionary, and illocutionary. According to Austin (1962) speech acts exhibit three main characteristics, which are perlocutionary, locutionary, and illocutionary acts. A locutionary act consists of the actual meaning of the words in an utterance and is also called the surface meaning. On the other hand, illocutionary act points to the meaning the speaker intended to convey, other than the words' meaning. Lastly, the real meaning of a said utterance is called the perlocutionary act (Austin, 1962). Basing themselves mainly on verb use and functions, both Searle (1969) and Austin (1962) proposed a classification of illocutionary acts as below:

1) Assertive (Representative) are those speech acts wherein the truth of a statement is assured by the speaker (e.g., description or depiction)

2) Commissive refer to those utterances wherein the speaker makes some future commitments such as a promise, swear or guarantee

3) Directives are the utterances in which a listener is expected to act as directed, hence the name of the directive is formulated (i.e., a request, a command)

4) Expressives are the utterances in which a speaker expresses sentiments in words, such as to thank, welcome, apologize, etc.

5) Declarative refer to those speech acts wherein the speaker alters a reality of himself or others and brings about a change, such as to take an oath, resign, nominate, etc. In the $21^{\text {st }}$ century, the comparative analysis of speech acts has garnered much attention from wider research. Cultural knowledge of the target language, an essential characteristic of communicative competence, is obligatory if a speech act has to be befitting in a social setup (Umale, 2011). Although speech acts are quintessentially universal, the impact of cultural diversity on their use offers potentially dynamic areas of inquiry. Since the 
current paper is focused on refusals as employed by Saudi EFL graduates, this section lists definitions and reviews of cross-cultural and intra-cultural research studies about refusal speech acts.

\subsection{Refusal Speech Acts}

Umale (2011) has defined the refusal speech act as, "face-threatening act that tends to disrupt harmony in relationships" (p. 18). This definition involves an unwillingness to decline or accept, also known as reluctance, as well as negative feedback to an invite, offer, and/or request (Sattar et al., 2011, p. 70). Therefore, refusal as a challenging type of speech act requires considerable pragmatic competence, for it may be received in a different light by the interlocutors. According to Umale (2011), refusal strategies which often cause harm to a speaker's positive self-image or face and endanger a listener's negative face are the result of multiple social factors, like interlocutors' status, academic level, the focus of the talk, surroundings, age difference, and gender. However, the noticeable multiplicity in the application of refusal strategies may be ascribed to cultural diversity. Different cultures appear to be marginally different in their use of speech acts, as claimed by many researchers in comparative cultures. Many such studies on cultural differences of use of refusals, and this study too, rely on the seminal effort by Beebe, Takahashi, andUliss-Weltz (1990), who formulated categorization and methodology for studying refusal speech acts. They categorized refusal strategies into adjuncts and semantic formulas. Adjunct, as the name suggests, aids to refusal utterances but cannot stand alone as a refusal in itself. In this regard Moaveni (2014) developed an argument in his Master's dissertation on refusal strategies of U.S and international students that "a semantic formula can be a full sentence, a phrase or even a word or words, and serves the function of a refusal in its entirety". He proposed and further elaborated on Beebe et al.'s (1990) taxonomy. This paper uses Moaveni's (2014) model of classifications while customizing it with the addition of adjunct strategies.

Table 1. Classification of Refusals (Semantic formulas \& Adjuncts)

\section{Direct}

A. Performative (I decline)

B. Non-performative

1. "No"

2. Negative willingness/ability ( "I can't" "I don't think so")

\section{Indirect}

A. Statement of regret ("I'm sorry..."; "I feel terrible...")

B. Wish ("I wish I could help you...")

C. Excuse, reason, explanation("My children will behome that night."; "I haveaheadache.")

D. Statement of alternative

1. I can do X instead of Y ("I'd rather..." "I'd prefer...")

2. Why don't you do X instead of Y ("Why don't you ask someone else?")

E. Set condition for future or past acceptance ("If you had asked me earlier, I would have...")

F. Promise of future acceptance ("I'll do it next time"; or "Next time I'll. .."

— using" will" of promise or "promise")

G. Statement of principle ("I never do business with friends.")

H. Statement of philosophy (“One can't be too careful.")

I. Attempt to dissuade interlocutor.

1. Threat or statement of negative consequences to the requester ("I won't be any fun tonight" to reuse an invitation)

2. Guilt trip (wait about a visitor just sitting longer after a small order: "I can'tmake living offpeople who just ordercoffee.")

3. Criticize the request/requester, etc. (statement of negative feeling or opinion); insult/attack ("Who do you think you are?"; "That's a terrible idea!")

4. Request for help, empathy, and assistance by dropping or holding the request.

5. Let interlocutor off the book ("Don't worry about it." "That's okay." "You don't have to.") 
6. Self-defense ("I 'm trying my best." "I'm doing all I can do.")

J. Acceptance that functions as a refusal

1. Unspecific or indefinite reply

2. Lack of enthusiasm

K. Avoidance

1. Nonverbal
a. Silence
b. Hesitation
c. Do nothing
e. Physical departure

2. Verbal
a. Topic switch
b. Joke
c. Repetition of part of a request, etc. (e.g., "Monday?")
d. Postponement (e.g., "I'll think about it.")
e. Hedging (“Gee, I don’t know." "I’m not sure.”)

\section{Adjuncts}

A. Statement of positive opinion/feeling or agreement ("That's a good idea. ..")

B. Statement of empathy ("I realize you are in a difficult situation.")

C. Pause fillers ("uhm"; "well”; "oh"; "uhm")

D. Gratitude/Appreciation

(Moaveni, 2014, p. 15)

In this taxonomy, direct and indirect refusals are further branches of semantic formulas. In the direct category there are performative utterances e.g. "I do not agree", "I decline", and non-performative utterances like, "No" or "I can't". On the contrary, the use of indirect realizations, characteristically accompanied by excuses, explanations, alternatives, etc., the person refusing eases the face-threatening act to minimize the adverse impression. Adjuncts are usually either pre-refusals or post-refusals since their appearance is either before or after semantic formula. They cannot be used for performing a refusal. Since the taxonomy propounded by Beebe et al. (1990) has widely been applied to the analysis of refusals in the plethora of research studies over the last 20 years, the researcher has also employed it for analyzing the use of refusal strategies by Saudi EFL students.

\subsection{Research Studies on Refusal Strategies in EFL Context}

According to Morkus (2014), refusal studies are divided into three categories: learner-focused, where the aim is to discover how language learners use refusal in different cultures; cross-cultural, where refusal is investigated from the perspective of different cultures; and intra-lingual, where refusal acts are studied within one language or culture. Beebe et al. (1990) contributed a great deal in the studies regarding refusal acts across cultures, by setting up for achievements in this field. They elicited comparative refusal findings by employing DCT on American native speakers and EFL students of Japan. After a rigorous analysis of refusal strategies, they identified three areas in which the American natives and Japanese EFL learners exhibited variations, i.e., in their structure, regularity, and substance of semantic formulae. The American native speakers of English showed a tendency to provide specificity while explaining anything, whereas Japanese participants provided elaborations that might be considered unclear by native speakers. Interestingly, Japanese speakers would get quite indirect while talking to anyone higher in the social order. The subsequent paragraphs present a critical review of studies carried out in different contexts while maintaining focus on learners and cross-cultural settings.

In his study Demir (2003), chose four sets of participants and employed DCT with 12 situations (which comprised of equal offers, invites, requests, and suggestions). These groups or sets of participants did the test in the following scheme i.e., English speaking natives attempting the test in English, Turkish speaking natives doing a similar assessment in their native language, Turkish EFL speakers attempting the same in the English language, Turkish EFL speakers attempting this assessment in their native language. The results depicted that even if there were commonalities between the subjects, EFL speakers of Turkish origin employed nearly the same method of responding in both Turkish and English. This result was not similar to the responses of natives of Turkish and English. Moreover, the social care of the speaker and listener was a deciding factor in the adopted manner of response in communication.

In another study, Henstock (2003) while using DCT attempted to compare refusals of American natives, Japanese natives, and foreign speakers of Japanese. The study concluded that American natives use negative 
politeness with all kinds of audience, while Japanese natives used this strategy only when communicating with a listener with higher social status. The study also concluded that the Japanese sense of frankness exhibits in their use of language with an interlocutor of similar or lower social rank.

In another study, Tanck (2004) conducted an analysis comparing native English speakers and EFL speakers (Korean, Spanish, and Mexican descent mostly) to examine the pattern and frequency of their complaints and refusals. According to her findings, EFL speakers used a few speech acts denoting complaints or refusal, compared to native speakers. Also, the appropriateness of their speech acts was misplaced in most of the cases.

In another study, Al-Eryani (2007) conducted a pragma-linguistic inquiry on 20 EFL students of Yemeni descent using DCT, to examine their refusal strategies in a foreign language. Their responses were gauged in the light of refusal classification by Beebe et al (1990), for sequencing of semantic patterns. Results were evident of the cultural variation that affected the content and frequency of the semantic formula, even though both language groups possessed similar refusal speech acts. The findings also pointed to the fact that some contexts also weighed in on the use of semantic formulae, such as the situations of suggesting, offering, invitation, and request, based on the stature of the speaker and listener.

Chang (2009) investigated Chinese EFL speakers for the "pragmatic transfer in refusals" and tried to gauge the extent to which this transfer is a learner's command over a second or foreign language, which is English. For this purpose, he chose to administer DCT as an elicitation instrument to four groups of participants. These groups included 40 Chinese-major sophomores (CC), 40 English-major freshmen (FE), 41 English-major seniors (SE), and 35 American college students (AE). The findings of this study demonstrated a pattern of frequency and content variation in semantic formulae of these participants even though in responding to the refusals elicited by different initiating acts they demonstrated a similar range of semantic formulas.

In a similar research inquiry, Capar (2014) used DCT with two different language groups, English and Turkish. Surprisingly less direct strategies were opted for by both of these classes of participants and among those, "explanation, reason and excuse" were favored by the majority. Power or status was assessed as a key catalyst in choosing the right strategy, by both language groups. On the other hand, direct strategies were opted for in case the communication is taking place between interlocutors of the same social status, whereas indirect strategies were voted for the situations involving class differences between the parties. Moreover, the traces of pragmatic transfer were also noticed which were ascribed to the students' weakness is pragmatic and grammatical abilities.

In another study, Hedayatnejad, Maleki \& Mehrizi (2015) explored similar strategies on 60 EFL learners of intermediate level in Iran to find the correlation of applied and realized strategies with refusals. This study was carried having gender differences also explored since there was an equal number of male and female participants. The analysis of data elicited through 18 conditions DCT projected that students made use of less direct strategies when communicating with equal social status individuals, as opposed to more prominent and direct refusal methods meted out to lower social cadre. The EFL learners used rather adjunct strategies to those with the same social stature. Moreover, refusing a suggestion, in both applied and realized manner, did not show any statistical difference when analyzed across male and female respondents belonging to all social classes.

In another study, Al-Mahrooqi and Al-Aghbari (2016) investigated the pragma-linguistic and socio-pragmatic dimensions of refusals exhibited by $41 \mathrm{EFL}$ college students of Omani descent having completed a 12 -situation DCT, producing their impressions to an equal number of offers, invitations, suggestions, and requests. The results of this study provided the readings that students' feedback was largely inaccurate. Furthermore, the influence of the students' culture was conspicuous, as many responses were discovered to be actual Google Translations of their Arabic responses converted, hence defeating the purpose. The findings underscored their learning of direct common speech acts used with teachers and peers at their college, in English.

Rezvani, Ismael, \& Tok (2017) examined the strategies of refusal used by 50 ELT majors from a university in Cyprus. The data was obtained from a 12-situation DCT, which was meant to elicit written responses. It was later checked in light of categorization of refusal strategies laid down by Beebe et al. (1990). The results indicated a tilt towards refusing indirectly. Moreover, more direct refusal was opted for by men when interacting with someone from a low social cadre, whereas women opted for direct refusals to an equal status recipient. Surprisingly, men used fewer adjuncts than women in the tested situations. Persian participants employed adjuncts in their speech more than the other ethnicities included in the research. Only Turk, EFL learners chose more direct strategies than other groups.

Another study by Alzeebaree and Yavuz (2018) explored the pragma-linguistic and socio-pragmatic abilities of 83 undergraduate EFL participants, of Kurdish origin, and 14 native speakers of English through a 6-situations DCT, containing 3 refusals and 3 suggestions. The findings of this study brought to light different patterns of 
strategy adoption by natives and Kurdish EFL learners, primarily due to their L1 interference. There was also some variation of responses due to the variable of place of study, state-run or privately owned universities.

Refusal strategies in response to invitations have been examined by Alsairi (2019) who compared Saudi ESL learners of advanced level in Britain, with Saudi ESL Learners of advanced level studying inside KSA. This study catered to L1 cultural interference and influence related to social power and distance. Data in this research was collected using a 6-situations role play and was analyzed for response strategies laid down by Tseng (1999) and Beebe et al (1990). This study brought to light stark differences between refusal strategies used by Saudi students in Britain and Saudi students studying English in KSA.

In a study, Alghamidi and Alqarni (2019) chose a demographic of American and Saudi female ESL learners for studying refusal patterns used in requests and invitations. It based itself on the semantic matter and the frequency of their speech acts when communicating with people of varying social statuses. Data collected through DCT reflected that the collectivist nature of Arab culture has a strong bearing on the way Arab EFL learners employ refusal strategies and are very sensitive about the face of the other person. This is brought to compare and contrast with a rather detached and individualistic milieu of American culture, which is relatively relaxing and direct in using refusal strategies.

D. A. El-Dakhs (2020) investigated how university professors react to students' requests. She studied 60 faculty members at a private Saudi university where English is the medium of instruction to see how they implemented the speech act of refusal. The teachers' rejection tactics, adjuncts, and modifiers were coded as part of the data obtained by role-playing. The findings revealed a strong preference for indirect tactics, small use of internal strategies, and little impact of gender and teaching experience on implementation strategies. The findings were discussed concerning the politeness principle, as well as the use of English as a second language.

\subsection{Research Gap}

A thorough perusal of literature reveals the importance as well as the relevance of further research to study refusal strategies of EFL students in their respective cultural surroundings and underpinnings, using DCT. Due to the paucity of research studies in the context of Saudi EFL students, the research has been motivated to explore the potentially researchable area which may be of use to the language instructors as well as a worthy addition to the existing body of research on speech acts in different EFL contexts. Based on the overview presented above, this study aims at a further inquiry in the same direction and explore further strands of refusal strategies. The following section outlines the method and methodology employed by this research, as well as the context.

\section{Methodology}

\subsection{Participants}

The study was conducted at the Department of English (Moon University, Saudi Arabia) during Fall Semester, 2020. Employing a convenient sampling procedure, it was administered to 20 EFL learners (male) enrolled in the BS English program $\left(3^{\text {rd }}\right.$ semester). The students were informed of the extent of their involvement and objectives of the study. Their participation was completely voluntary, and they were assured of complete anonymity and confidentiality of their responses.

\subsection{Data Collection Procedure}

For the acquisition of data on refusal strategies used by Saudi EFL learners, the participants were given a Discourse Completion Test (DCT), which is a common method and instrument in pragmatic research. This method is a way of obtaining data while monitoring the study's variables and providing statistical descriptions (Olshtain, 1993). The DCT used in this study has been adapted from Tuncern (2016) which is grounded in the contribution of Beebe et al. (1990) and Umale (2011). Tuncern (2016) has already proven the validity and reliability of the DCT. However, the DCT was first piloted to three students who were then asked for their opinion on face validity and content.

The researcher administered the instrument himself to the participants during the class and explained the instruction orally for more clarity. The Discourse completion test (DCT) contained 12 scenarios that required the respondents to provide refusals in writing, to an equal number of offers, invitations, suggestions, and requests. A refusal response to an interlocutor with a different social status was required in these situations. The three situations in each category elicited responses from interlocutors of lower, equal, and higher social classes respectively. The participants took 40 minutes to complete the DCT. A detailed appendix presents all the presented situations to the respondents. The structure of the DCT items is as follows: 
Table 2. Structure of the DCT Items

\begin{tabular}{lll}
\hline Situations & Item no. & Status of the interlocutor \\
\hline requests & 1 & Low- High \\
& 2 & Equal \\
suggestions & 12 & High- Low \\
& 5 & Equal \\
invitations & 6 & High- Low \\
& 3 & Low- High \\
& 4 & Low- High \\
offers & 10 & High- Low \\
& 7 & Equal \\
& 9 & Low- High \\
& 11 & Equal \\
\hline
\end{tabular}

DCT was used in this study to achieve two main objectives, i.e., to capture a higher level of control that existed in given responses, provided situations and variables of context; and to provide a cultural and linguistic comparison with a whole body of studies around the same constructs in refusal strategies.

\subsection{Data Analysis and Procedure}

The data obtained from participants were coded using Beebe et al. (1990)'s refusal strategy classification, which is one of the widely used taxonomies for refusal studies. The data was then evaluated using descriptive statistics (frequencies and percentages) and then presented in the tabular form to come up with clear conclusions about how Saudi EFL undergraduates used refusal tactics. To exemplify the process of analysis, a response from a participant is analyzed below into further smaller chunks,

Example response for Item 4

You: I don't accept invitations because I have to do my office work that day. $2 \mathrm{G}$ (statement of principle) $+2 \mathrm{C}$ (Excuse, reason, explanation)

\section{Results}

The collected data has been assessed for its content, in the light of the taxonomy of refusal strategies laid down by Beebe et al. (1990). The data of 20 participants were analyzed using descriptive statistics, providing several refusal strategies adopted for each speech act through a figure demonstrating refusal strategies in response to other speech acts followed by a comprehensive table given below.

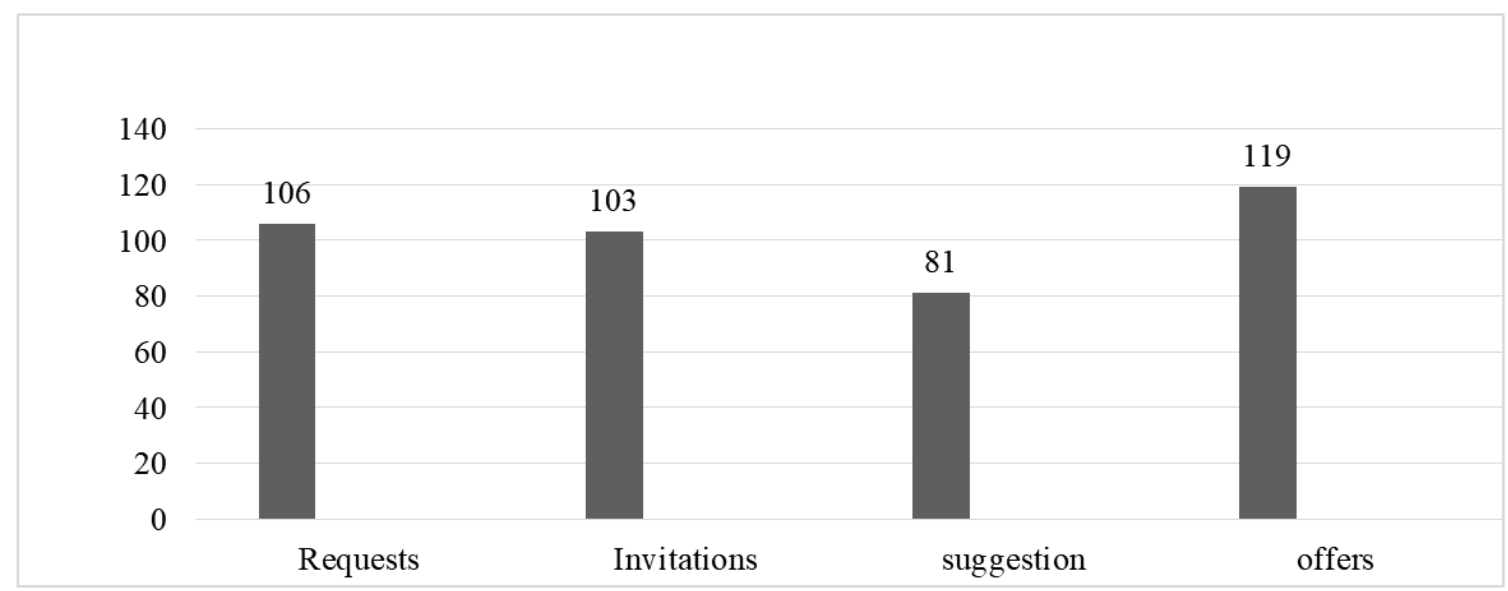

Figure 1. Refusal Strategies in Response to Other Speech Acts

Figure 1 demonstrates that speech act of offers elicits the greatest number of responses, and it is covered by items 7, 9, and 11. Requests are the second most common type of speech, and items 1, 2, and 12 fall into this 
category. Invitations are placed on the third number in the order, which includes items 3,4 , and 10 . The fourth number corresponds to the speech act of suggestion, and refusal items 5, 6, and 8 fall into this range.

The following table is adapted from a frequency table formation adopted by Tuncer (2016) in his paper about Turkish instructors employing refusal strategies.

Table 3. Frequency Count of Refusal Strategies Usage

\begin{tabular}{lcc}
\hline Refusal Strategies & Requests Invitations Suggestions Offers & Total \\
& & Frequency \\
\hline
\end{tabular}

\section{Direct Strategies}

1A (Performative- e.g., 'I refuse')

00

00

00

$--\quad 00$

1B1 (No)

04

08

$21 \quad 34$

1B2 (Negative willingness/ability) (e.g., "I can't." "I

11

11

22

won't." "I don't think so.")

\section{Indirect Strategies}

2A (Statement of regret) (e.g., "I'm sorry ..."; "I feel 38

$38 \quad 34$

14

$12 \quad 98$

terrible ...")

2B (Wish) (e.g., "I wish I could help you ...")

00

2C (Excuse, reason, explanation)

2D1 (I can do X instead of Y) (e.g., "I'd rather ..."; "I'd prefer ...")

2D2 (Why don't you do X instead of Y) (e.g., "If you had 01 asked me earlier, I would have.")

2E (Make past or future conditional with some arguments. e.g., "If she has spoken to me on the phone, it would have been.)

2F (Promise of future acceptance) (e.g., "I'll do it next time"; "I promise I'll ..." or "Next time I'll ..." -- using "will" of promise or "promise")

2G (Statement of principle) (e.g., "I never do business with 01 friends.")

2H Statement of philosophy (e.g., "One can't be too careful.")

2I Try to discourage the listener

$2 \mathrm{I} 1$ (Intimidate or state negative results to other party inviting) (e.g., "You would regret my coming to your place)

2I2. Guilt trip (e.g., waitress to customers who want to sit a while: "I can't make a living of people who just order coffee?")

2I3 Disapprove the request (state bad sentiments/intention) 02 e.g. "You think I care? That's a terrible idea!")

2I4 Asking for support in the manner of accepting or rejecting a request

2I5 Let interlocutor off the hook (e.g., "Don't worry about 05 it." "That's okay." "You don't have to.")

2I6 Self-defense (e.g., "I'm trying my best." "I'm doing all 01 I can do." "I no do nutting wrong.")

2J1Acceptance which can be understood as rejection (unclear reply)

$2 \mathrm{~J} 2$ Devoid of rigor or excitement 
2K. Escaping (Nonverbal) 2K1 Silence, 2K2 Hesitation,

2K3 Doing nothing 2K4 Physical departure

2K2 Avoidance (Verbal)

$2 \mathrm{~K} 2 \mathrm{a}$. Topic switch

2K2b Joke

$2 \mathrm{~K} 2 \mathrm{c}$ Reproducing the partial request to assure etc. (e.g., "Monday?"),

2K2d (Postponement) (e.g., "I'll think about it.") 01

2K2e (Hedging) (e.g., "Gee, I don't know." "I'm not sure.”)

\section{Adjuncts}

ADJ1 (Showing affirmative stance) (e.g., "That's a good 04 idea..." "I'd love to...")

ADJ2 (Statement of empathy) (e.g., "I realize you are in a difficult situation.”)

ADJ3 (Pause fillers) (e.g., "uhh"; “well”; “oh"; "uhm”)

ADJ4 (Statement of gratitude or appreciation) (e.g., "thanks"; "I really appreciate it")

Overall frequencies of refusal requests

01

$01 \quad 01$

106

103

07

$01 \quad 14$

Table 4. Refusal Strategies for Requests

\begin{tabular}{|c|c|}
\hline Refusal Strategies for Requests & Frequency \\
\hline \multicolumn{2}{|l|}{ Direct Strategies } \\
\hline 1A (Performative- e.g., 'I refuse') & 00 \\
\hline $1 \mathrm{~B} 1(\mathrm{No})$ & 04 \\
\hline 1B2 (Negative willingness/ability) (e.g., "I can't." "I won't." "I don't think so.") & 11 \\
\hline \multicolumn{2}{|l|}{ Indirect Strategies } \\
\hline 2A (Statement of regret) (e.g., "I'm sorry ..."; "I feel terrible ...") & 38 \\
\hline 2B (Wish) (e.g., "I wish I could help you ...") & 00 \\
\hline 2C (Excuse, reason, explanation) & 25 \\
\hline 2D2 (Why don't you do X instead of Y) (e.g., "If you had asked me earlier, I would have.") & 01 \\
\hline \multicolumn{2}{|l|}{$\begin{array}{l}\text { 2F (Promise of future acceptance) (e.g., "I'll do it next time"; "I promise I'll ..." or "Next time I'll ..." --04 } \\
\text { using "will" of promise or "promise") }\end{array}$} \\
\hline 2G (Statement of principle) (e.g., "I never do business with friends.") & 01 \\
\hline 2H Statement of philosophy (e.g., "One can't be too careful.") & 00 \\
\hline 2I Try to discourage the listener & 01 \\
\hline \multicolumn{2}{|l|}{$\begin{array}{l}2 \mathrm{I} 1 \text { (Intimidate or state negative results to other party inviting) (e.g., "You would regret my coming to } \\
\text { your place) }\end{array}$} \\
\hline \multicolumn{2}{|l|}{$\begin{array}{l}\text { 2I3 Disapprove the request (state bad sentiments/intention) e.g. "You think I care? That's a terrible } 02 \\
\text { idea!") }\end{array}$} \\
\hline 2I5 Let interlocutor off the hook (e.g., "Don't worry about it." "That's okay." "You don't have to.") & 05 \\
\hline 2I6 Self-defense (e.g., "I'm trying my best." "I'm doing all I can do." "I no do nutting wrong.") & 01 \\
\hline 2K2d (Postponement) (e.g., "I'll think about it.") & 01 \\
\hline \multicolumn{2}{|l|}{ Adjuncts } \\
\hline ADJ1 (Showing affirmative stance) (e.g., "That's a good idea..." "I'd love to...”) & 04 \\
\hline ADJ3 (Pause fillers) (e.g., “uhh”; “well”; “oh”; “uhm”) & 03 \\
\hline ADJ4 (Statement of gratitude or appreciation) (e.g., "thanks"; "I really appreciate it") & 05 \\
\hline Overall frequencies of refusal requests & 106 \\
\hline
\end{tabular}


Table 5. Refusal Strategies for Invitations

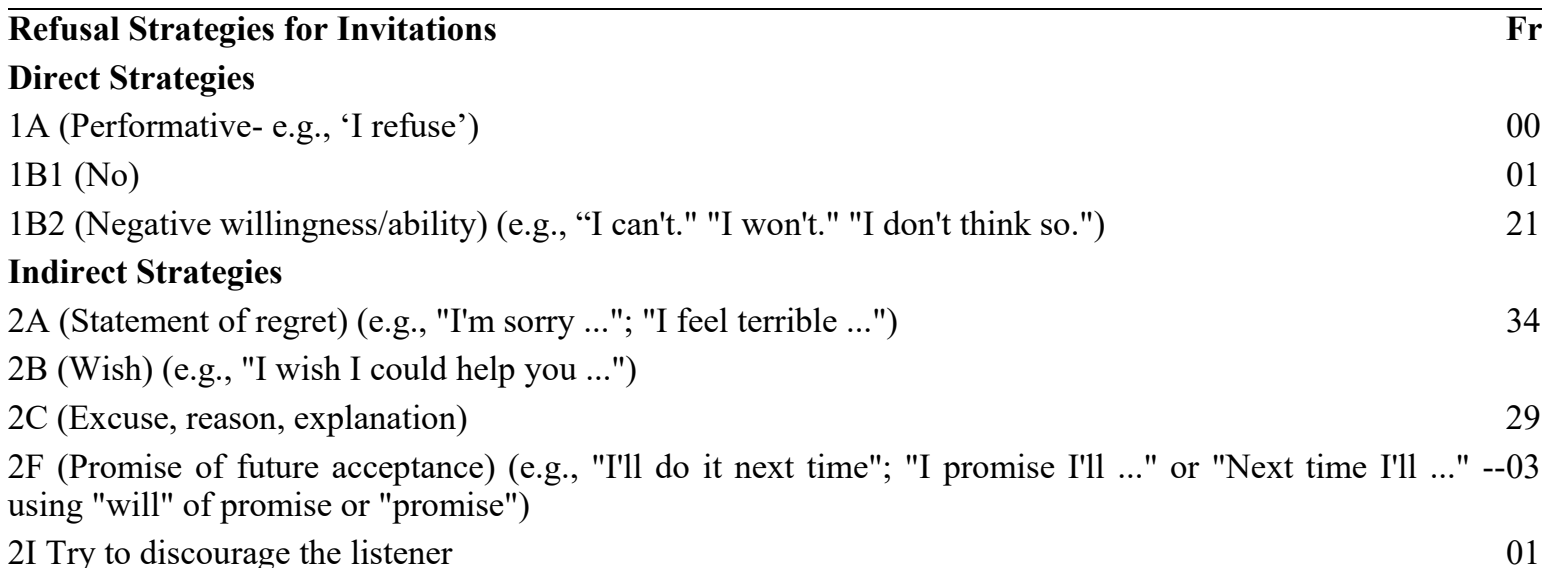

2I1 (Intimidate or state negative results to other party inviting) (e.g., "You would regret my coming to your place)

2I5 Let interlocutor off the hook (e.g., "Don't worry about it." “That's okay." "You don't have to.") 02

2K2d (Postponement) (e.g., "I'll think about it.") 01

2K2e (Hedging) (e.g., “Gee, I don't know." "I'm not sure.”) 03

Adjuncts

ADJ1 (Showing affirmative stance) (e.g., "That's a good idea..." "I'd love to...”) 02

ADJ4 (Statement of gratitude or appreciation) (e.g., "thanks"; "I really appreciate it") 06

$\begin{array}{lr}\text { Overall frequencies of refusal requests } & 103\end{array}$

Table 6. Refusal Strategies for Suggestions

\begin{tabular}{|c|c|}
\hline Refusal Strategies for Suggestions & Frequency \\
\hline \multicolumn{2}{|l|}{ Direct Strategies } \\
\hline 1A (Performative- e.g., 'I refuse') & 00 \\
\hline $1 \mathrm{~B} 1(\mathrm{No})$ & 08 \\
\hline 1B2 (Negative willingness/ability) (e.g., "I can't." "I won't." "I don't think so.") & 11 \\
\hline \multicolumn{2}{|l|}{ Indirect Strategies } \\
\hline 2A (Statement of regret) (e.g., "I'm sorry ..."; "I feel terrible ...") & 14 \\
\hline 2C (Excuse, reason, explanation) & 09 \\
\hline \multicolumn{2}{|l|}{$\begin{array}{l}\text { 2F (Promise of future acceptance) (e.g., "I'll do it next time"; "I promise I'll ..." or "Next time I'll ..." --02 } \\
\text { using "will" of promise or "promise") }\end{array}$} \\
\hline 2G (Statement of principle) (e.g., "I never do business with friends.") & 05 \\
\hline 2H Statement of philosophy (e.g., "One can't be too careful.") & 07 \\
\hline \multicolumn{2}{|l|}{$\begin{array}{l}\text { 2I2. Guilt trip (e.g., waitress to customers who want to sit a while: "I can't make a living of people who just } 01 \\
\text { order coffee?") }\end{array}$} \\
\hline 2I3 Disapprove the request (state bad sentiments/intention) e.g. "You think I care? That's a terrible idea!") & 07 \\
\hline 2I5 Let interlocutor off the hook (e.g., "Don't worry about it." "That's okay." "You don't have to.”) & 02 \\
\hline 2I6 Self-defense (e.g., "I'm trying my best." "I'm doing all I can do." "I no do nutting wrong.”) & 01 \\
\hline 2K2d (Postponement) (e.g., "I'll think about it.”) & 01 \\
\hline 2K2e (Hedging) (e.g., “Gee, I don't know." "I'm not sure.”) & 02 \\
\hline \multicolumn{2}{|l|}{ Adjuncts } \\
\hline ADJ1 (Showing affirmative stance) (e.g., "That's a good idea..." "I'd love to...”) & 07 \\
\hline ADJ3 (Pause fillers) (e.g., “uhh”; “well”; “oh”; “uhm”) & 01 \\
\hline ADJ4 (Statement of gratitude or appreciation) (e.g., "thanks"; "I really appreciate it”) & 03 \\
\hline Overall frequencies of refusal requests & 81 \\
\hline
\end{tabular}


Table 7. Refusal Strategies for Offers

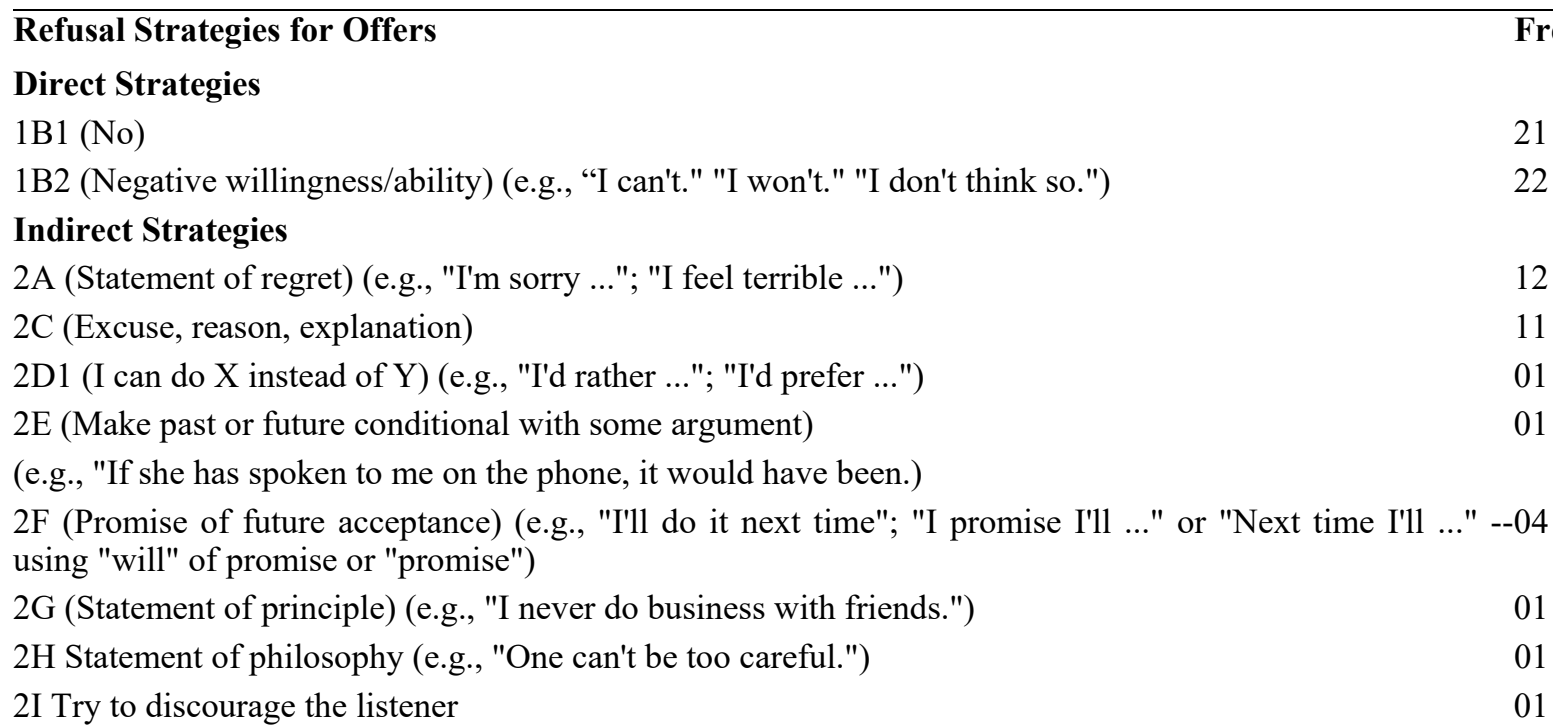

2I1 (Intimidate or state negative results to other party inviting) (e.g., "You would regret my coming to your place)

2I2. Guilt trip (e.g., waitress to customers who want to sit a while: "I can't make a living of people who just02 order coffee?")

2I3 Disapprove the request (state bad sentiments/intention) e.g. "You think I care? That's a terrible idea!") 03

2I5 Let interlocutor off the hook (e.g., "Don't worry about it." "That's okay." "You don't have to.") 19

2K2a. Topic switch

\section{Adjuncts}

ADJ1 (Showing affirmative stance) (e.g., "That's a good idea..." "I'd love to...")

ADJ2 (Statement of empathy) (e.g., "I realize you are in a difficult situation.")

ADJ3 (Pause fillers) (e.g., "uhh"; "well”; “oh"; "uhm")

ADJ4 (Statement of gratitude or appreciation) (e.g., "thanks"; "I really appreciate it")

\section{Discussion}

The speech act of offers elicits the greatest number of responses, and it is covered by items 7, 9, and 11 . Requests are the second most common type of speech, and items 1, 2, and 12 fall into this category. Invitations are placed on the third number in the order, which includes items 3, 4, and 10. The fourth number corresponds to the speech act of suggestion, and refusal items 5,6, and 8 fall into this range.

\subsection{Direct Strategies}

With the frequency count of 65 direct refusal strategy 1B2 (Negative willingness/ability) was also preferred especially in response to offers (22) invitations (21) whereas its preference responding to suggestions (11) and requests (11). Another direct strategy $1 \mathrm{~B} 1$ (No) was moderately preferred by respondents especially in response to offers (22) which can be ascribed to eastern culture in which offers are not accepted readily be it from the high-low, low-high or equal-equal scenario.

\subsection{Indirect Strategies}

Overall adoption of indirect refusal strategies by participants is visible in the results. Item $2 \mathrm{~A}$ garners the most of frequency count, of 98 and surpasses every other item in this DCT. The participants employed this strategy for refusing the speech acts of request (38) and invitations (34) whereas for suggestions (14) and offers (12) the frequency counts demonstrate an average use. With the frequency count of 74, $2 \mathrm{C}$ (statement of regret) turned out to be the second popular choice as an indirect method of refusal in response to invitations (29) and requests (25). It can be ascribed to Saudi culture because it is acknowledged as culturally rude if someone turns down an invitation without presenting any convincing excuse. It was due to this very factor that $2 \mathrm{C}$ was the hugely opted option in case refusal is offered as a reply to an invite. The whole premise for this choice revolves around the idea of honor and respect observed in Middle Eastern culture wherein an invitation means more than just 
socializing. It spells as the host would like to honor the guest and turning this offer down is taken as rude unless a very genuine reason is provided. The next most preferred strategy with a frequency score of 28 is 2I5 (Let interlocutor off the hook especially in response to offers (19) whereas it is least preferred while attending suggestions, invitations, and requests that demonstrate consideration for the feelings of the interlocutor. The preference for this strategy in response to invitations, suggestions, and requests is insignificant. The next indirect strategy with the frequency count of 13 is $2 \mathrm{~F}$ (Promise of future acceptance), especially in response to offers and requests. This use of strategy demonstrates care about the hope and feelings of an interlocutor to keep the social relationship intact. With the frequency count of 12, another strategy 2I3 (Criticize the request/requester (statement of negative feeling or opinion; insult/attack) is used in response to suggestions (7) which shows the element of directness in this indirect strategy. It is not preferred at all in response to invitations which shows consideration for "face." Another strategy $2 \mathrm{H}$ (Statement of philosophy) is employed by 8 respondents, especially in response to suggestions and is not preferred by any respondent in response to requests and invitations. This trend hints at the habit of philosophizing and lack of readiness in accepting suggestions by some respondents.

Another strategy $2 \mathrm{G}$ (Statement of principle) was preferred by five respondents in response to suggestions. Only one respondent each chose it for responding to requests and offers and none of them used it for invitations. Again a situation that hints at the inclination of people in portraying themselves as "a man of principle". An insignificant use of $2 \mathrm{~K} 2 \mathrm{e}$ (Hedging) points to an abject weakness in the pragmatic and linguistic abilities of respondents, with the frequency count of (5) in total and completely absent when responding to offers and requests. The use of hedges is, no doubt, often quite challenging for EFL learners (nonnative speakers).

The strategy $2 \mathrm{~K} 2 \mathrm{~d}$ (Postponement) is not preferred in response to offers whereas its use shows as low as one each for requests, invitations, and suggestions. The strategy 2 I6 (Self-defense) is employed with the frequency count as low as 2. Other strategies which are least preferred (3) by the respondents are 2-I (Try to discourage the listener) 2I1 (Intimidate or state negative consequences) and 2I2 Guilt trip (03). The strategies 2D1, 2D2 and 2E with the low-frequency rate of 1 each require grammatical constructions for which most of the EFL students lack the competence to make. Thus, it hints at the linguistic limitation of EFL students.

Other strategies such as $2 \mathrm{I} 4$ (Request for help/empathy/assistance by dropping or holding the request), 2J1 (Acceptance that functions as a refusal Unspecific or indefinite reply), 2K2 (Avoidance (Verbal), and 2K2c Repetition of part of the request, etc., are not preferred by the respondents in refusing offers, suggestions, invitations, and requests in a conversation. The controlled context for elicitation of refusal response in DCT does not allow for the use of 2K2b (Joke). Other non-verbal avoidance strategies in 2K Avoidance (Nonverbal) 2K1 Silence, 2K2 Hesitation, 2K3 Doing nothing 2K4 Physical are observable in role plays or in real life occurring data.

\subsection{Adjuncts}

With the aggregate frequency of 50 refusing using adjuncts (ADJ1, ADJ2, ADJ3 and ADJ4) appears to be the second most opted strategy. With the highest frequency of 28, ADJ 4 (Statement of gratitude or appreciation) is preferred by respondents in response to offers (14), invitations (6) requests (5) suggestions (03), which indicates a positive trend because Saudi society in general and EFL students are found to be negligent of expressing their gratitude and appreciation for others. The second highest frequency count (14) is evident in the use of ADJ1 (Statement of positive opinion) especially in response to suggestions (7) and requests (4) and quite nominal responding to offers (1) and invitations (2). The strategy ADJ3 (Pause fillers) is used a total of 7 times, with equal frequency responding to offers (3) and requests (3) and complete absence in response to invitations (00). The least preferred strategy is ADJ2 (Statement of empathy) which was opted only once with the frequency of 01 in response to offers(1) whereas it was not used while responding to suggestions, invitations, and requests, which might indicate the growing lack of empathy in the society and lack of socio-pragmatic competence in EFL students to tone down the effect of refusal which is the norm in the native culture of the English as well as the in the cross-cultural communication in this globalized world. Thus, it has become evident that most of the adjuncts have been used by the respondents for eliciting speech act in DCT.

\section{Conclusion}

To conclude, the current study describes the refusal strategies of Saudi EFL Students, considering the social standing of the participants in communication and the kind of speech acts adopted in such situations. A total of 409 strategies have been chosen by respondents in this research. The most employed strategies were indirect strategies, with a total of 325 , whereas the next choice was the adjuncts with the total frequency of 50 , and the third category, direct strategies exhibited the least frequency of 34. Due to the prevalent perception of directness 
being disrespectful in Arab culture, more indirect strategies have been chosen by Saudi participants of this research. Hence, to demonstrate courteousness for effective social communication, more indirect manners of refusals were opted for. The three most favored strategies comprised 2A (statement of regret) 2C (excuse, reason, explanation), and 1B2 (negative willingness/ability). In short, the speech acts of refusals are quite complex in nature, owing to the fact the interlocutors need to process the situations with sound pragmatic knowledge. A refusal has the potential to be interpreted differently by both parties in a conversation. When not executed carefully, a refusal can easily harm the pleasant image of a speaker, while challenging the negative face of the interlocutor, thus catalyzing communication breakdown. Therefore, the use of indirect strategies along with adjuncts may lower the disrupting and disharmonizing effect of direct refusal.

\subsection{Limitations of the Present Study and the Way Forward}

Like every research endeavor, this study had few limitations. Initially, owing to convenience sampling the small sample size from one discipline posed a limitation. Therefore, to have a generalization about Saudi EFL graduate students, studies with a larger sample size are recommended. Secondly inter-language and intra- language comparison of the use of speech acts, especially refusals, may further provide us guidelines as to the reverse impact of L2 on the first language conduct of speakers. Furthermore, a cross-gender comparison may emerge as a potential area for more research in refusal speech acts involving second language learning. Besides, the current study might be beneficial for EFL instructors in designing courses and their lessons primarily focused on the enhancement of both socio-pragmatic and pragma-linguistic competence.

\section{References}

Al-Eryani, A. A. (2007). Refusal strategies by Yemeni EFL students. The Asian EFL Journal Quarterly, 9(2), 19-34.

Alghamdi, N. A., \& R. Alqarni, I. (2019). A sociolinguistic study of the use of refusal strategies by Saudi and American females. SSRN Electronic Journal, 9(5). https://doi.org/10.2139/ssrn.3444233

Al-Mahrooqi, R., \& Al-Aghbari, K. (2016). Refusal strategies among Omani EFL students. SAGE Open, 6(4). https://doi.org/10.1177/2158244016672907

Alsairi, M. A. (2019). Analyzing the Saudi EFI advanced learners' refusal strategies: a pragmalinguistic perspective. British Journal of English Linguistics, 7(2), 15-43.

Alzeebaree, Y., \& Yavuz, M. (2018). Suggestion and refusal strategies in English by Kurdish undergraduate students. International Journal of English Linguistics, 8(5), 151. https://doi.org/10.5539/ijel.v8n5p151

Austin, J. L. (1975). How to do things with words. Oxford University Press. https://doi.org/10.1093/acprof:oso/9780198245537.001.0001

Beebe, L., T. Takahashi, \& R. Uliss-Weltz. (1990) Pragmatic transfer in ESL refusals. In R. Scarcella, E. S. Anderson, \& S. Krashen (Eds.), Developing Communicative Competence in Second Language (pp. 55-73). New York: Newbury House.

Brown, P., \& Levinson, S. C. (1987). Politeness: Some universals in language usage. Cambridge University Press. https://doi.org/10.1017/CBO9780511813085

Çapar, M. (2014). How do Turkısh EFL students say 'no'? International Journal of Language Academy, 2(3), 262-282. https://doi.org/10.18033/ijla.121

Chang, Y. (2009). How to say no: An analysis of cross-cultural difference and pragmatic transfer. Language Sciences, 31(4), 477-493. https://doi.org/10.1016/j.langsci.2008.01.002

Demir, S. (2003). Bidirectional pragmatic transfer: an investigation of refusal strategies of Turkish users of English (M.A. - Master of Arts). Middle East Technical University.

El-Dakhs, D. A. (2020). The art of saying "No" to university students: A pragmatic analysis of the speech Act of refusal in teacher-student role-plays. Journal of Language and Education, 6(4), 55-75. https://doi.org/10.17323/jle.2020.11271

Hedayatnejad, F., Maleki, R., \& Mehrizi, A. A. (2015). The effect of social status and gender on the realization of refusal of suggestion among Iranian EFL intermediate learners. Journal of Language Teaching and Research, 7(1), 99. https://doi.org/10.17507/j1tr.0701.11

Henstock, M. I. (2003). Refusals: A language and cultural barrier between Americans and Japanese [Doctoral dissertation]. 
Lightbown, P. M., \& Spada, N. (2013). How languages are learned - Oxford handbooks for language teachers (4th ed.). Oxford University Press.

Moaveni, H. T. (2014). A Study of Refusal Strategies by American and International Students at an American University (Master's thesis, Minnesota State University- Mankato). Retrieved from https://core.ac.uk/download/pdf/214117216.pdf

Morkus, N. (2014). Refusals in Egyptian Arabic and American English. Journal of Pragmatics, 70, 86-107. https://doi.org/10.1016/j.pragma.2014.06.001

Olshtain, E. (1993). The production of speech acts by EFL learners. TESOL Quarterly, 27, 33-56. https://doi.org/10.2307/3586950

Rezvani, M., Ismael, D. A., \& Tok, S. (2017). Speech Act of Refusal among English Language Teaching Students. International Journal of Research in Teacher Education, 8(2), 1-11.

Sattar, A, Q., Che Lah, C., \& Suleiman, R. (2011). Refusal strategies in English by Malay university students. Journal of Language Studies, 11(3), 69-81.

Searle, J. (1969). Speech acts: An essay in the philosophy of language. Cambridge, UK: Cambridge University Press. https://doi.org/10.1017/CBO9781139173438

Tanck, S. (2004). Speech Act sets of refusal and complaint: A comparison of native and non-native English speakers' production. TESOL Working Papers, Series 2.

Tuncern, H. (2016). Refusal strategies used by Turkish university instructors of English. Novitas-ROYAL, 10(1), 71-90.

Umale, J. (2011). Pragmatic failure in refusal strategies: British versus Omani interlocutors. Arab World English Journal, 2(1), 18-46. 


\section{Appendix}

\section{Discourse Completion Test}

Name (optional):

Gender

Age: Current Degree Program:

This questionnaire intends at gaining an insight into students' responses which they might give in a set of situations given in this DCT. Please read the twelve cases and imagine yourself in that role in real life so that you may give the most appropriate response in each situation.

Please consider the example given below and then fill out the blanks.

Example: You are employed in a departmental store. One day while helping the people at your shop, one of your regular customers' requests an object in the showcase.

You: Would you mind if I am with you in a minute? Excuse me for a minute.

Customer: Not at all.

Example: Being a superstore employee you are busy attending to a customer. A returning customer approaches you and requests for looking at an item on display.

You: My apologies, I will be will you shortly please.

Customer: Okay, I am here.

Case 1. You own a book shop. An employee there wishes to talk to you one to one in your office.

Worker: It has been more than a year of my work in this shop. You have expressed your satisfaction with my work too. I enjoy being part of this place. But due to my circumstances, I request a raise in my salary.

You:

Worker: I am afraid I may have to search for a job elsewhere in near future.

Case 2. In your college, you are a regular student and note down lectures carefully. Your class fellow asks you to share your notes because they are not very regular.

Classmate: Sorry, but I am too worried as we have an exam tomorrow. Can you let me have a look at your lecture notes, please? Please!

You:

Classmate: Hmm. Let me try to ask someone else then.

Case 3. You are a director of a traveling company and one of your colleagues requests you to join him for lunch at the son's graduation party.

Colleague: Sir, there is a modest graduation party for my son this weekend. It will be our honor if you please join us too.

You:

Colleague: No problem. Hope you can join us another time.

Case 4. Your CEO, in a law consultancy, reaches out to you and wishes to see you in person.

CEO: This Thursday there is a BBQ party at my place with some close friends. I realize it is a close call, but it will be good if you join with family. How about it?

You:

CEO: Oh, I wished you can join other directors at the get-together. 
Case 5. You are sleeping over at a cousin's place to watch a late-night football match together. You are offered fried chicken by him.

You: Please keep me away from this. It so tempting but I have had enough fast food lately and have gained a lot of weight.

Cousin: Got it. How about checking those weight-loss tea sachets I bought together with you from the superstore?

You:

Cousin: I recommend you try it still.

Case 6. You are anxiously looking for a presentation file, from the last meeting, your manager asked you to email in an over. The manager himself visits your workstation.

Manager: It is a good idea to stay organized. I make date-wise folders and keep them in cloud storage. You better start doing it too.

You:

Manager: There is always room for trying better things to stay organized.

Case 7. Arriving home, you realize that your maid appears nervous.

Maid: Forgive me for the damage that happened when I was dusting the table. The marble decoration piece slipped from my hand. Kindly deduct it from my salary.

You: (realizing that maid is the only earning hand of her family.)

Maid: I insist that I should pay.

Case 8. Being an ESL instructor after the first periodical a student approaches to discuss a matter with you in a corridor.

Student: Sir, being the CR, I speak on behalf of the class. Is it possible if we get some more chances to speak besides grammar lessons?

You:

Student: No problem Sir. As you think best for us.

Case 9. There is lunch at your brother's place. You are all sitting to eat.

Brother: Try this chocolate cake. It's homemade.

You:

Brother: It's very tasty. Try at least?

You:

Case 10. You are invited to a tea party at a family friend's house. You are not very fond of this person.

Friend: What are you doing this Friday? Why not join us for a cup of tea?

You:

Friend: No excuses next time. Ok?

Case 11. It has been a year since you joined Bin Dawood. You are loving your job and HR calls you and discusses a promotion opportunity in another city. You cannot leave your current location. The manager sees you in his office to talk about it.

Manager: We are opening a new store in Thuwal and you can get a good promotion and salary there. It is just 2 hours from here. 
You:

Manager: Take some more time to think and discuss at home. Such opportunities do not come very often.

Case 12. The meeting in the office is getting longer and you have to reach home to be able to reach a doctor's appointment on time.

Presenter: If it is ok with everyone, we can stay a little longer to finish off this proposal discussion today and save all of us a lot of time.

You:-

Boss: Oh. We wish you were here throughout. No worries you will get the minutes in email.

\section{Copyrights}

Copyright for this article is retained by the author(s), with first publication rights granted to the journal.

This is an open-access article distributed under the terms and conditions of the Creative Commons Attribution license (http://creativecommons.org/licenses/by/4.0/). 